\title{
Water Scarcity and Urban Forest Management: Introduction
}

Between 1997 and 2009, a serious drought affected much of Australia. Water demand in excess of supply resulted in water restrictions for private and public landscapes and increased water prices. Historically, most trees were located in turf and irrigated with sprinkler systems. The restrictions on irrigation resulted in significant damage to the health of many trees. Expenditures for managing drought-stressed landscapes and removing dead trees skyrocketed, while ecosystem services produced by formerly healthy trees were foregone. The increased water prices accelerated landscape water conservation efforts, further stressing trees least able to adapt. At a time when health advocates, stormwater managers, and sustainability city planners were promoting the environmental, social, psychological, and economic benefits of healthy urban forests, trees were dying at unprecedented rates. Whether reasoned or unintentional, water policy decisions closed the tap, turning much of the urban forest's lifeline to a trickle. Green infrastructure became brown infrastructure, exposing its standing as a low priority relative to other consumptive sources. Policy makers and researchers began to consider a new question, "How much water should be allocated for urban landscapes?" In response to catastrophic tree losses, municipal foresters, landscape architects, and others began developing and testing new irrigation technologies, harvesting and reusing rainfall, selecting drought-tolerant species, and managing soil to detain and infiltrate runoff.

The Australian response to this crisis-both its successes and its setbacks-offer important lessons that can inform others. In the United States, cities in the southeast and west have experienced drought and irrigation restrictions. Climate change is expected to result in more extreme weather events, and water scarcity may become a new norm in certain parts of the world.

This special issue of Arboriculture \& Urban Forestry resulted from a symposium held July 25-27, 2011 at the 2011 International Society of Arboriculture Annual Conference \& Trade Show (Sydney, Australia). The purpose of the symposium, organized by Greg McPherson and co-convened by Nelda Matheny and Larry Costello, was to share new solutions to water scarcity and urban forest management. The articles herein offer "lessons learned" to inform future policy, research, design, and management.

\section{E. Gregory McPherson}

Research Forester

USDA Forest Service

\section{Robert Prince}

Chief Executive Officer

Nursery and Garden Industry Australia 